\title{
0.0IASIOH
}

Available online at Website http://ejournal.undip.ac.id/index.php/rotasi

\section{INVESTIGASI GEOMETRI DAN PERFORMA HIDRODINAMIS PROPELER PRODUKSI UKM PADA KONDISI OPEN WATER}

\author{
*Fiki Firdaus, Jamari, Rifky Ismail \\ Jurusan Teknik Mesin, Fakultas Teknik, Universitas Diponegoro \\ Jl. Prof. Sudharto, SH, Tembalang, Semarang 50275 \\ *Email: fikifirdaus@yahoo.co.id
}

\begin{abstract}
ABSTRAK
Untuk menghasilkan sebuah produk kapal yang beroperasi secara efisien dan juga dapat menghemat bahan bakar, tidak cukup dengan hanya optimalisasi parameter lambungnya, sistem propulsi juga harus disesuaikan menurut bentuk lambung kapal dan motor induk serta sistem transmisi yang digunakan. Dalam kenyataan dilapangan, banyak ditemukan bahwasanya penggunaan propeler untuk kapal tidak memperhitungkan aspek teknis, berupa daya mesin, gaya dorong kapal, dan sebagainya. Produksi propeler oleh pihak UKM juga tidak memperhitungkan kesesuaian antara geometri propeler dengan geometri kapal. Pada penelitian ini dibahas tentang geometri propeler produk UKM, geometri kapal, dan performa hidrodinamis propeler pada kondisi air terbuka (open water). Hasil investigasi yang didapatkan diantaranya geometri propeler berupa $\mathrm{D}=640 \mathrm{~mm}$; $\mathrm{P} / \mathrm{D}=1.28$; dan $\mathrm{BAR}=0.50$. Selanjutnya performa hidrodinamis pada kondisi air terbuka dengan $\mathrm{KT}=0.152 ; \mathrm{KQ}=0.0334$ dan $\eta_{\mathrm{o}}=0.731$ pada $\mathrm{J}=1.01$.
\end{abstract}

Kata kunci: Efisiensi, performa hidrodinamis, sistem propulsi

\section{PENDAHULUAN}

Dalam bidang maritim kita telah memiliki galangan kapal yang berkemampuan membangun kapal tanker, kapal barang, kapal tunda, kapal keruk dan kapal-kapal khusus lainnya serta peralatan untuk tambang lepas pantai. Namun dibalik kemampuan dan kemajuan teknologi, masih banyak pula terdapat bagian dari kehidupan negara maritim ini yang masih belum menerapkan ilmu teknologi dengan baik, misalnya untuk kapal-kapal nelayan.

Pembangunan kapal secara tradisional ini memang jauh dari teknologi modern dan mempunyai banyak kelemahan yang harus mendapatkan perhatian lebih dalam rangka perbaikan [1]. Untuk menghasilkan sebuah produk kapal yang beroperasi secara efisien dan juga dapat menghemat bahan bakar, tidak cukup dengan hanya optimalisasi parameter lambungnya, sistem propulsi juga harus disesuaikan menurut bentuk lambung kapal dan motor induk serta system transmisi yang digunakan [2].

Selain memproduksi kapal tradisional, di Kab. Tegal terdapat UKM yang juga mampu membuat komponen kapal, diantaranya adalah propeler (baling-baling kapal). Namun pembuatan propeler ini mempunyai kendala. Salah satunya adalah desain propeler yang masih belum banyak berkembang, karena hanya mengandalkan "insting" bukan aspek teknik dalam proses desain dan manufakturnya.

Metode teoritis untuk memprediksi kinerja propeler berkembang dimulai dari teori momentum Rankine, diikuti oleh teori blade elemen dari Froude [3]. Tahun 1990an, para ilmuwan menyederhanakan model baling-baling dengan model komputasi, dan memulai penelitian kalkulasi geometri riil baling-baling dengan model rumusan RANS (Reynolds Averaged Navier Stokes). Selanjutnya membuka ruang yang luas dalam perhitungan hidrodinamika balingbaling dengan tipe seri yang lain [1]. Secara umum kinerja propeler ditampilkan dalam parameter nondimensional berupa koefisien gaya dorong $\left(K_{T}\right)$, koefisien torsi $\left(K_{Q}\right)$, dan efisiensi propeler $\left(\eta_{0}\right)$ [4-7].

Dalamoperasinya dilaut, suatu kapal harus memiliki kemampuan untuk mempertahankan kecepatan dinas (Vs) seperti yang direncanakan. Hal ini mempunyai arti bahwa, kapal haruslah mempunyai rancangan sistem propulsi (penggerak) yang dapat mengatasi keseluruhan gaya-gaya hambat (total resistance) yang terjadi agar memenuhi standar kecepatan dinasnya [8].

\section{METODOLOGI PENELITIAN}

Untuk data terkait sistem propulsi kapal, pengambilan data dilakukan di galangan kapal kayu milik KUD Karya Mina di Tegalsari, Tegal. Sedangkan data propeler diambil di sentra UKM pengrajin propeler Artha Mandiri di Kebasen, Tegal. Dalam penelitian ini, alat dan bahan yang digunakan adalah sebagai berikut:

1. Model peropeler produk UKM

2. Alat ukur (mistar baja, jangka sorong, micrometer)

3. Perangkat keras/ hardware: laptop

4. Perangkat lunak/ software : DELFTship, FREE!ship 
Tahapan penelitian tersebut dijelaskan oleh diagram penelitian sebagai berikut:

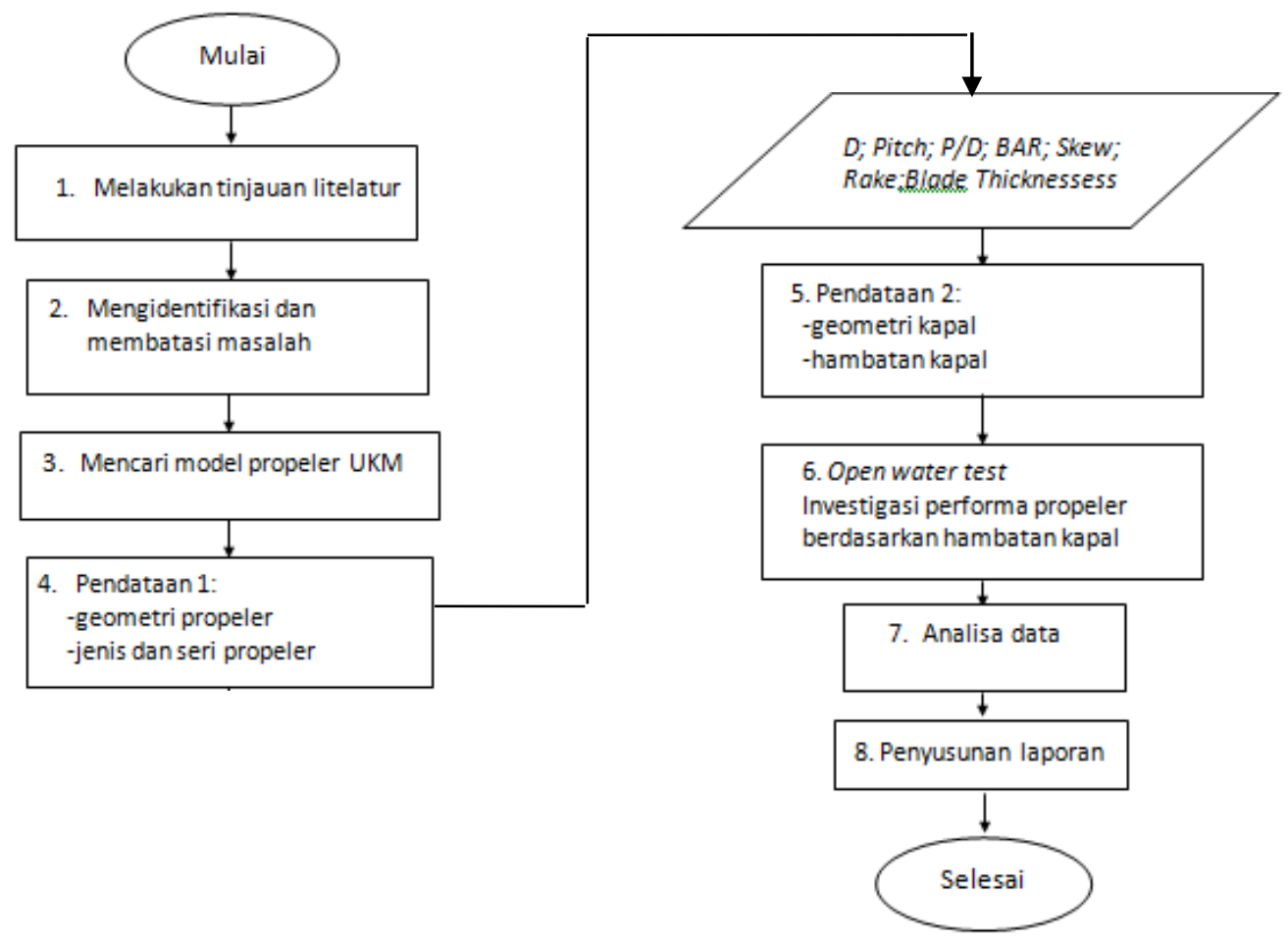

Gambar 1. Flowchart penelitian adalah:

Beberapa tahapan penelitian yang akan dilakukan dalam penyelesaian penelitian tentang propeler produksi UKM

1. Studi literatur, kunjungan lapangan, wawancara, dan bimbingan.

2. Mencari model propeler UKM.

3. Model propeler UKM yang dijadikan objek penelitian pada Gambar 2

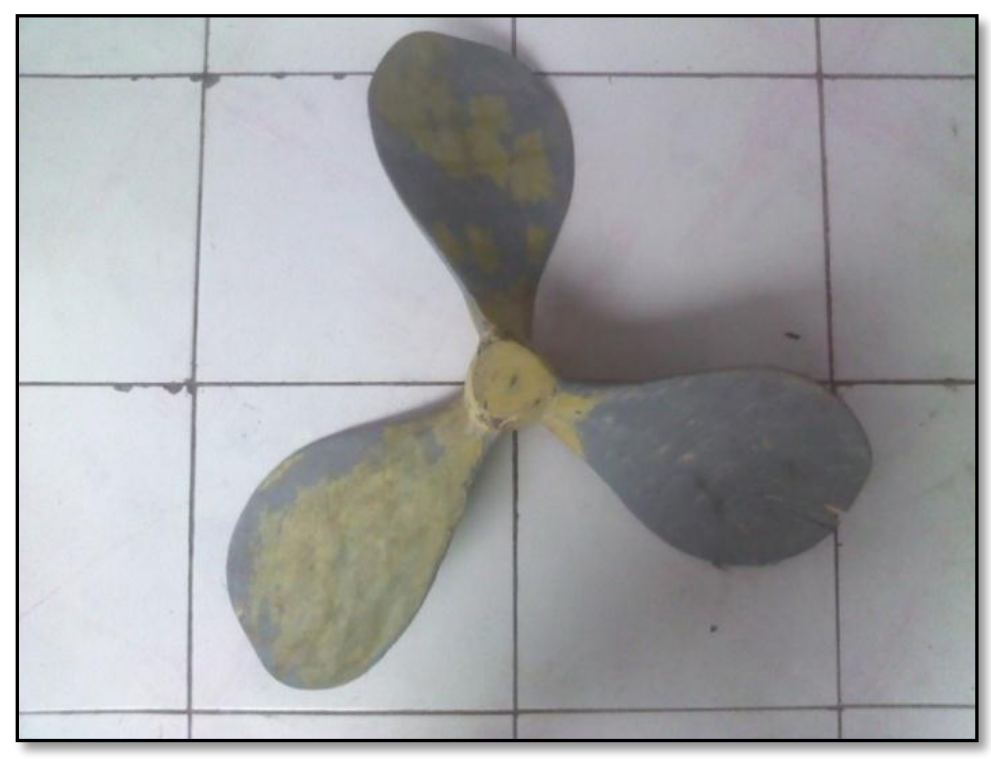

Gambar 2. Model propeler produk UKM

4. Mencari data geometri model propeler UKM

5. Investigasi seri propeler produk UKM melalui data geometri hasil pengukuran sebelumnya.

6. Mencari geometri model kapal.

7. Investigasi performa hidrodinamis dan efisiensi propeler pada kondisi open water. 
Gambar 3 berikut adalah kapal tradisional yang dijadikan salah satu objek penelitian.

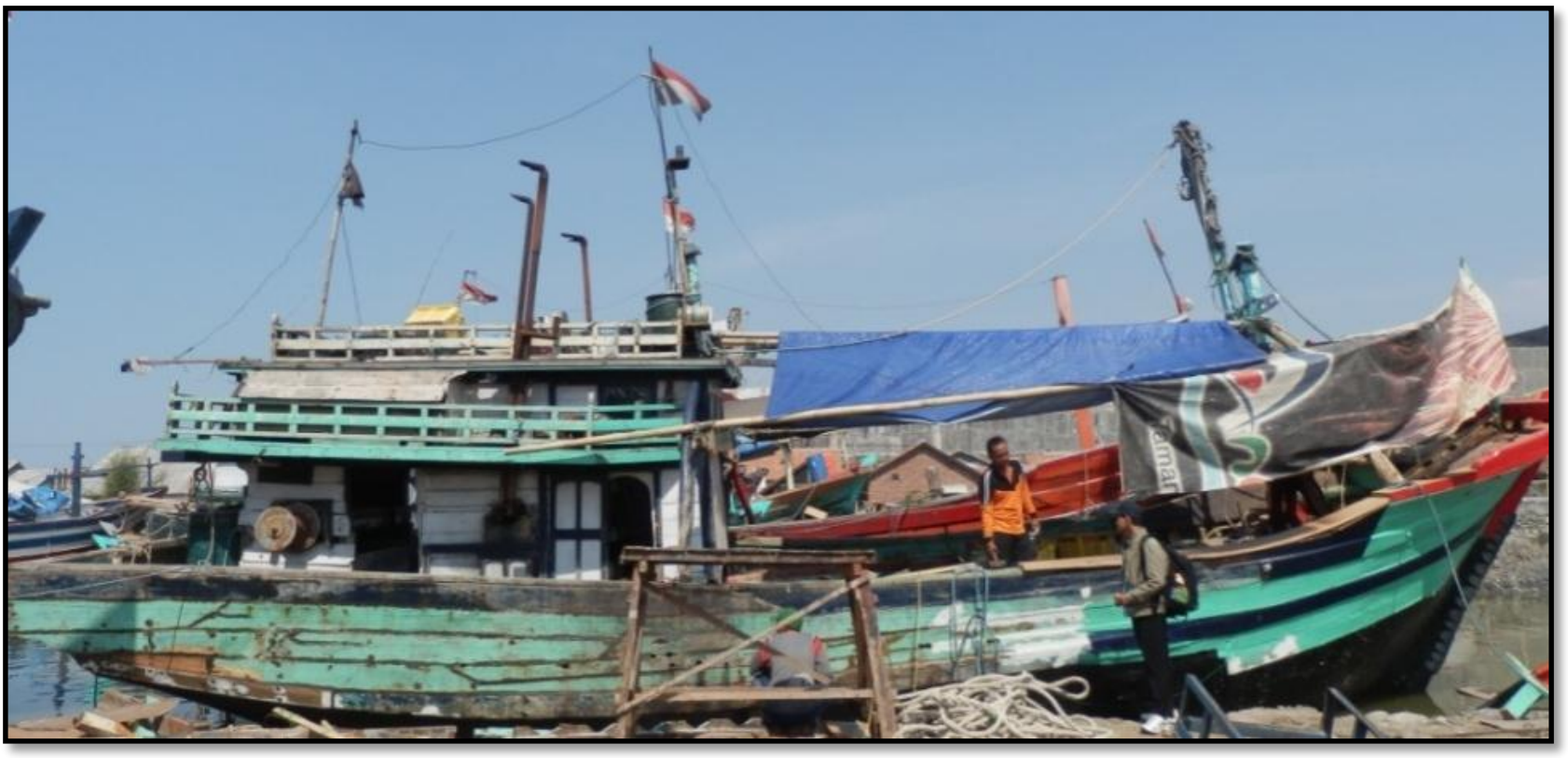

Gambar 3. Kapal nelayan objek penelitian

\section{HASIL DAN PEMBAHASAN}

\subsection{Geometri Propeller}

Berdasarkan pengukuran manual pada model propeler produk UKM, geometri yang diperoleh berupa diameter, pitch, dan blade thickness, serta hasil perhitungan manual berupa pitch ratio dan blade area ratio. Hasil pengukuran dan perhitungan manual selengkapnya pada tabel 1 dan 2 .

Tabel 1. Data Geometri propeler

\begin{tabular}{llc}
\hline Parameter & Nilai & Satuan \\
\hline Diameter (D) & 640 & $\mathrm{~mm}$ \\
Pitch (P) & 819.2 & $\mathrm{~mm}$ \\
Pitch ratio (P/D) & 1.28 & - \\
Blade area ratio & 0.50 & - \\
Rake & 0 & $\left(\mathrm{n}^{\circ}\right)$ \\
Skew & 0 & $\left(\mathrm{n}^{\circ}\right)$ \\
\hline
\end{tabular}

Tabel 2. Data chord length dan blade thickness propeler

\begin{tabular}{ccc}
\hline$r / R$ & $c(r)[\mathrm{mm}]$ & $t(r)[\mathrm{mm}]$ \\
\hline 0.20 & 110 & 23 \\
0.25 & 120 & 21 \\
0.30 & 135 & 19.5 \\
0.40 & 164 & 17 \\
0.50 & 198 & 15 \\
0.60 & 220 & 13 \\
0.70 & 217 & 10.5 \\
0.80 & 202 & 7.5 \\
\hline
\end{tabular}




\subsection{Investigasi Jenis Serial Propeler Produk UKM}

Dari data gemoetri propeler sebelumnya, untuk $Z=3 ; A_{E} / A_{o}=0.50 ; P / D=1.28 ; D=640 \mathrm{~mm}$, maka dapat disimpulkan bahwa propeler produk UKM merupakan salah satu dari fixed pitch, non-ducted proppeller dengan jenis Wageningen B-series [3].

Tabel 3. Wageningen B-series dan produk UKM

\begin{tabular}{lcccc}
\hline \multicolumn{1}{c}{ Propeller } & $\boldsymbol{Z}$ & $\boldsymbol{A}_{\boldsymbol{E}} / \boldsymbol{A o}_{\boldsymbol{o}}$ & $\boldsymbol{P} / \boldsymbol{D}$ & $\boldsymbol{D}(\mathbf{m m})$ \\
\hline Wageningen B-series & $2-7$ & $0.3-1.05$ & $0.6-1.4$ & 250 \\
Produk UKM & 3 & 0.50 & 1.28 & 640 \\
\hline
\end{tabular}

\subsection{Geometri kapal}

Data geometri kapal yang digunakan adalah kapal tradisional kayu dimana kapal tersebut dibuat di galangan Tegal. Geometri yang didapat adalah hasil pengukuran di galangan, kemudian perhitungan yang lain dengan bantuan software DELFTship. Hasil pengukuran kapal di galangan selengkapnya adalah pada tabel 4 dan tabel 5 berikut :

Tabel 4. Data kapal

\begin{tabular}{lll}
\hline No & Data & \\
\hline 1 & Nama kapal & KM Maju Jaya \\
2 & Kapasitas tertulis & Mitsubishi Colt Diesel 4 Silinder \\
3 & Engine & 110 HP \\
4 & Daya mesin maksimal & $2900 \mathrm{rpm}$ \\
5 & Putaran maksimal & $4: 1$ \\
6 & Gearbox ratio & Full displacement \\
7 & Tipe lambung & 1 (single engine) \\
8 & Jumlah mesin & 1 (single propeller) \\
9 & Jumlah propeler & 7 knots \\
10 & Kecepatan dinas & \\
\hline
\end{tabular}

Tabel 5. Data geometri kapal

\begin{tabular}{llll}
\hline No & Parameter & Satuan & Hasil pengukuran \\
\hline 1 & Length over all $($ Loa $)$ & $\mathrm{m}$ & 16.15 \\
2 & Length water line $(\mathrm{Lwl})$ & $\mathrm{m}$ & 14.4 \\
3 & Breadth over all $($ Boa $)$ & $\mathrm{m}$ & 3.7 \\
4 & Breadth of water line $(B w l)$ & $\mathrm{m}$ & 3.4 \\
5 & Breadth $($ B $)$ & $\mathrm{m}$ & 3.5 \\
6 & Draught $(T)$ & $\mathrm{m}$ & 1.4 \\
7 & Immersion $(\mathrm{I})$ & $\mathrm{m}$ & 0.6 \\
\hline
\end{tabular}

Berdasarkan data geometri kapal yang didapat, peneliti menggunakan software Free!ship untuk mencari hambatan kapal. Selengkapnya pada tabel 6

Tabel 6. Data tahanan kapal

\begin{tabular}{|c|c|c|c|c|c|c|c|}
\hline V (kt) & $R T(\mathbf{N})$ & $P E(k W)$ & $W$ & $T$ & $\operatorname{Req.Thr}(\mathbf{N})$ & $\eta H$ & $\eta R$ \\
\hline 1 & 42.2 & 0.02 & 0.2239 & 0.2319 & 55 & 0.9896 & 1.0198 \\
\hline 2 & 153.7 & 0.16 & 0.2157 & 0.2319 & 200.2 & 0.9793 & 1.0198 \\
\hline 3 & 328.8 & 0.51 & 0.2118 & 0.2319 & 428.1 & 0.9744 & 1.0198 \\
\hline 4 & 571.4 & 1.18 & 0.2093 & 0.2319 & 743.9 & 0.9713 & 1.0198 \\
\hline 5 & 937 & 2.41 & 0.2075 & 0.2319 & 1220 & 0.9691 & 1.0198 \\
\hline 6 & 1606.6 & 4.96 & 0.2061 & 0.2319 & 2091.8 & 0.9674 & 1.0198 \\
\hline 7 & 2983.2 & 10.74 & 0.205 & 0.2319 & 3884.1 & 0.966 & 1.0198 \\
\hline 8 & 4659.9 & 19.18 & 0.204 & 0.2319 & 6067.1 & 0.9649 & 1.0198 \\
\hline
\end{tabular}

Berdasarkan data tahanan kapal pada tabel 6, required thrust kapal pada kecepatan 7 knot adalah sebesar $3.8 \mathrm{KN}$ dimana diperoleh hambatan total (RT) sebesar $2.9 \mathrm{KN}$. 


\subsection{Investigasi Performa Hidrodinamis Propeler}

Investigasi performa hidrodinamis propeler pada kondisi open water menggunakan software FREE!ship, dengan input parameter berupa tipe propeler, disk area ratio $\left(A_{E} / A_{0}\right)$, pitch ratio $(P / D)$, jumlah blade $(z)$, putaran propeller $(n)$, diameter $(D)$, dan kecepatan aliran air pada propeler $\left(V_{a}\right)$. Hasil investigasi performa hidrodinamis propeler dapat dilihat pada gambar 5 dan tabel 7.

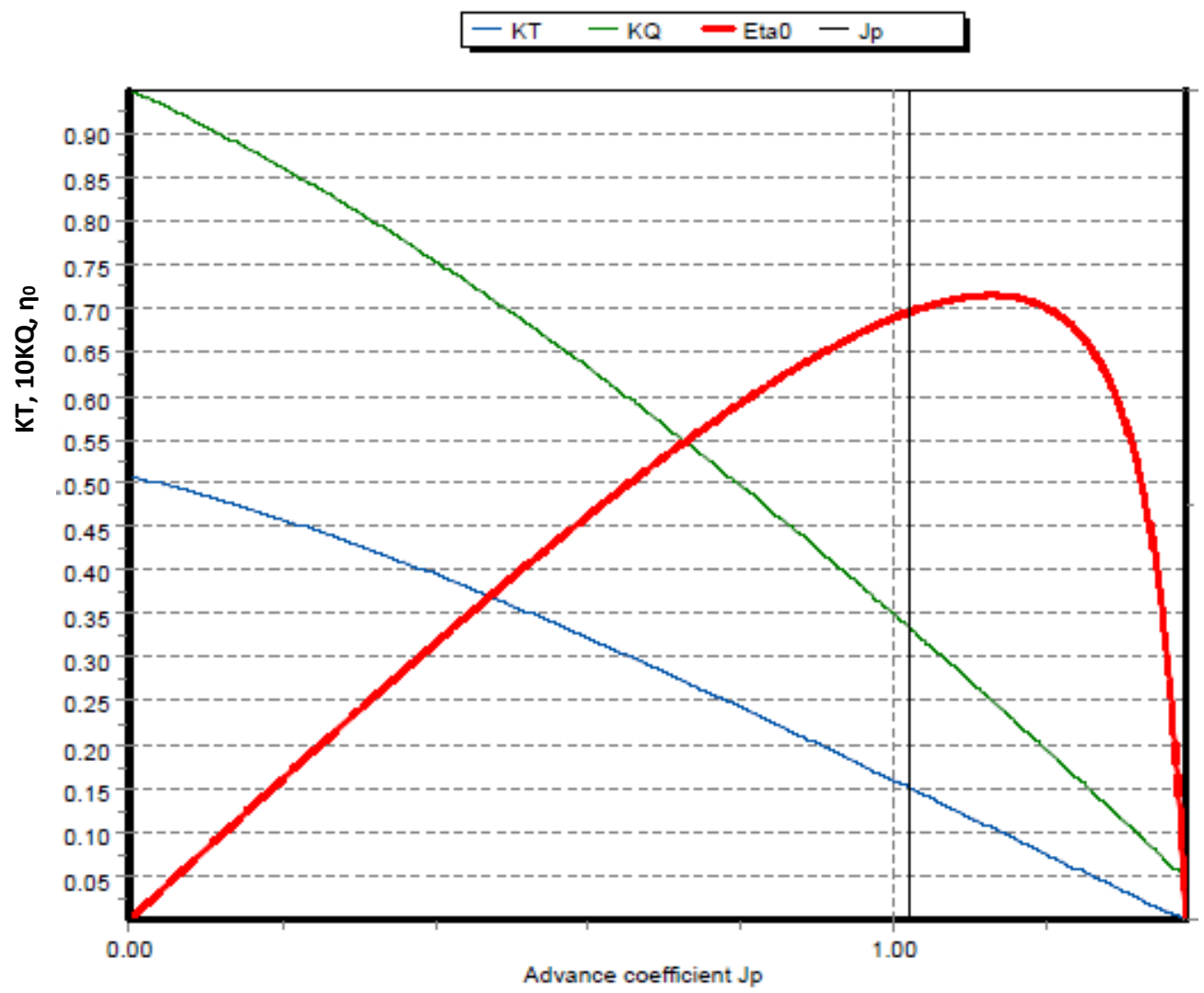

Gambar 4. Output FREE!ship: Open Water Curve

Tabel 7. Hasil perhitungan performa open water

\begin{tabular}{clcc}
\hline \multicolumn{1}{c}{ Parameter } & Symbol & Number \\
\hline No & & $J_{p}$ opt & 1.127 \\
2 & Optimal advance coeffic. & $\eta_{0}$ max & 0.7527 \\
2 & Maximum efficiency & $J p T_{0}$ & 1.38 \\
3 & Zero thrust advance coeff. & $J p Q_{0}$ & 1.436 \\
4 & Zero torque advance coeff. & $J p$ & 1.0176 \\
5 & Estimated advance & $T$ & 0.504 \\
6 & Propeller thrust $[k N]$ & $Q$ & 0.071 \\
7 & Propeller torque $[k N m]$ & $\eta_{0}$ & 0.7318 \\
8 & Efficiency & $P_{b}$ & 1.442 \\
9 & Brake power $[k W]$ & $P_{d}$ & $1.971(2.678)$ BHP \\
10 & Propeller power $[k W]$ & & \\
\hline
\end{tabular}

Berdasarkan hasil operasi program FREE!ship, dihasilkan efisiensi performa propeler $\eta_{\mathrm{o}}=0.7318$ dengan koefisien advance $\mathrm{J}=1.0176$ pada kecepatan $\mathrm{V}_{\mathrm{s}}=7$ knot dan putaran propeler $\mathrm{n}_{\mathrm{s}}=263.67 \mathrm{rpm}$.

\section{KESIMPULAN}

Dari hasil investigasi geometri sesuai dengan tabel 3, maka dapat disimpulkan, seri dari jenis propeller produk UKM adalah jenis non-ducted fixed propeller, dengan seri wageningen B-series. Performa hidrodinamis pada kondisi air tebuka pada kecepatan kapal 7 knot dihasilkan $\mathrm{KT}=0.152$ dan $\mathrm{KQ}=0.0334$, dengan efisiensi $\left(\eta_{0}\right)$ sebesar 0.731 pada $\mathbf{J}=1.01$. Propeler produk UKM memiliki efisiensi yang tinggi, namun tidak cocok untuk digunakan pada kapal yang digunakan dalam penelitian ini, dikarenakan tidak memenuhi req.thrust kapal sebesar $3.8 \mathrm{KN}$ pada kecepatan 7 knot, sedangkan propeler produk UKM hanya dapat menghasilkan thrust sebesar $0.5 \mathrm{KN}$ pada kecepatan 7 knot. 


\section{REFERENSI}

[1] P. Agung, dan H. Anita, 2014, “Analisa Karakteristik Baling-Baling B Series Di Air Terbuka Dengan CFD”, KAPAL-Vol 11, No1, PPNS, Surabaya.

[2] Sukadana, I.B.P., 2002, “Resistance Test Model Kapal Ikan Tradisional di Brondong”, Laporan Penelitian DUELik, PPNS: Surabaya.

[3] Carlton, J., 2007, “Marine Propellers and Propulsion”, Elsevier, Butterworth-Heineman Ltd.

[4] Kuiper, G., 1992, "The Wageningen Propeller Series", MARIN Publication, Wageningen.

[5] Man, 2012, "Basic Principles of Ship Propulsion", Man Diesel \& Turbo.

[6] Oosterveld, M.W.C. dan Oossanen, P. van, 1972, "Recent development in marine propeller hydrodynamics", Netherlands Ship Model Basin (MARIN).

[7] Oosterveld, M.W.C. dan Oossanen, P. van, 1975, "Further computer-analyzed data of the Wageningen B-screw series", International Shipbuilding Progress.

[8] Adji, Suryo. W., 2006, "Pengenalan Sistem Propulsi”, ITS, Surabaya 